\title{
Clinical Teaching: Sixty Tips for Successful Implementation
}

\section{Haitham Mohamed El Bingawi ${ }^{1}$ and Ali Hendi Alghamdi² \\ ${ }^{1}$ Department of Medicine, College of Medicine, Al Baha University, Saudi Arabia \\ ${ }^{2}$ Department of Surgery, College of Medicine, Al Baha University, Saudi Arabia}

\section{Abstract}

Background: A good planning of clinical teaching which is followed by systematic implementation results in better training outcomes. This paper defines the detailed roles of tutor, students, patients, and the clinical learning environment from the planning phase to what should be done post the session. It relies on the idea of using checklist (tips). Our hypothesis is that checklist summarizes all relevant information in a single abstraction.

Corresponding Author: Haitham Mohamed El Bingawi;

Department of Medicine, College of Medicine, Al Baha University, Saudi Arabia email: halbenjawi@bu.edu.sa

Received 8 June 2020

Accepted 14 July 2020

Published

30 September 2020

Production and Hosting by Knowledge E

(c) Haitham Mohamed El Bingawi and Ali Hendi

Alghamdi. This article is

distributed under the terms of the Creative Commons

Attribution License, which permits unrestricted use and redistribution provided that the original author and source are credited.

Editor-in-Chief:

Prof. Mohammad A. M. Ibnouf

\section{G OPEN ACCESS}

Methods: A literature review of various databases such as PubMed, Google scholar, and Cochrane with different search terms and search strategies were done. Qualitative and quantitative studies published in English in the aforementioned databases, discussing both the concepts of clinical teaching as well as the roles of tutor, students, patients, and environment were reviewed. In addition, authors' experience as clinical educators were further used to define the variables. The term tips are used to refer to the steps in a checklist.

Results: Sixty tips were identified. These tips highlight the roles and characteristics of: clinical tutors (26 tips), students (18 tips), clinical environment (8 tips), and patients (8 tips).

Conclusions: These tips serve as a mini guide to everyone who conduct clinical teaching to medical students in the ward.

Keywords: clinical teaching, planning, implementation tips, checklist

\section{Introduction}

Medical curricula have undergone a major revolution over the last decade - it has moved to more integration between basic and clinical sciences; in addition, new innovative technologies such as high fidelity simulation are also being used in the training [1]. However, despite this remarkable improvement, the overall conduct of the clinical teaching is still suboptimal [2]. The structured schedule of the new curricula is often faced with many challenges; of these, the inconsistency between the theoretical and clinical teaching is the most pertinent one. For example, if the theoretical teaching is centered around diseases of the nervous system, bedside teaching may not cover the 
same diseases because they may not be available at that time. This gap is further widened by the growing change in patient-doctor relationship, decreased facultystudents' ratio, busy tutors, the rapid change of training regulations, and the suboptimal preparation of teaching. Therefore, it is quite evident that for clinical teaching to succeed and attain its goal, it requires more than scheduling in the timetable. Multiple strategies have to be applied. Simulation as an adjunct to teaching in the ward seems to have many advantages. In addition to preparing students for the real-life experience, it helps bridging the gap between theory and practice. Additionally, one of the important, yet often ignored, strategies to improve clinical teaching, is the good, objective-based, and meticulous planning and implementation $[3,4]$.

Planning is the thinking process that precedes the implementation of teaching. The plan turns in to training program that achieves the predetermined objectives within the limits of the available resources. Therefore, the success of teaching is measured by the extent of its ability to achieve the desired objectives. This cannot be achieved without proper and organized planning. Critical to the discussion, it is necessary to define and coordinate the role of all parties involved in training, namely, the trainer, the students, the patients, and the training environment for the success of the clinical session.

This article defines the detailed roles of tutor, students, patients, and the clinical learning environment (CLE). It describes the planning phase, conduction, and finally what should be done post session. It relies on the idea of using checklist (tips). Our hypothesis is that checklist summarizes all relevant information in a single abstraction.

\section{Methods}

To determine the roles of tutor, students, patients, and the teaching environment in clinical teaching and to develop comprehensive Checklist (tips) associated with them; we carried out a review of the literature in databases such as PubMed, Google scholar, and Cochrane with different search strategies. Search terms like "teaching in clinical setting", "bedside teaching", "preparation of clinical teaching", "planning of clinical teaching", "implementation tips/steps of clinical teaching", "roles of tutors in clinical teaching", "students role in clinical teaching", "patients role in teaching", and "the role of the clinical environment" were used. In this way, we covered both the literature discussing the concepts of clinical teaching as well as the roles of tutor, students, patients, and environment in its conduction. Qualitative and quantitative studies published in English were reviewed. Moreover, we used our experience as clinical educators to define the different roles in clinical teaching. 
The term tips are used to refer to the steps in a checklist. Checklist is defined as the "list of action items or criteria arranged in a systematic manner, allowing the user to record the presence/absence of the individual items listed to ensure that all are considered or completed" [5].

\section{Result}

Sixty tips were identified. These tips are grouped under four headings: tips related to the tutor (26 tips), tips related to students (18 tips), tips related to CLE (8 tips), and tips related to patients (8 tips). The clinical session preparation cycle designed by the authors are easy-to-use strategy, as presented in Figure 1.

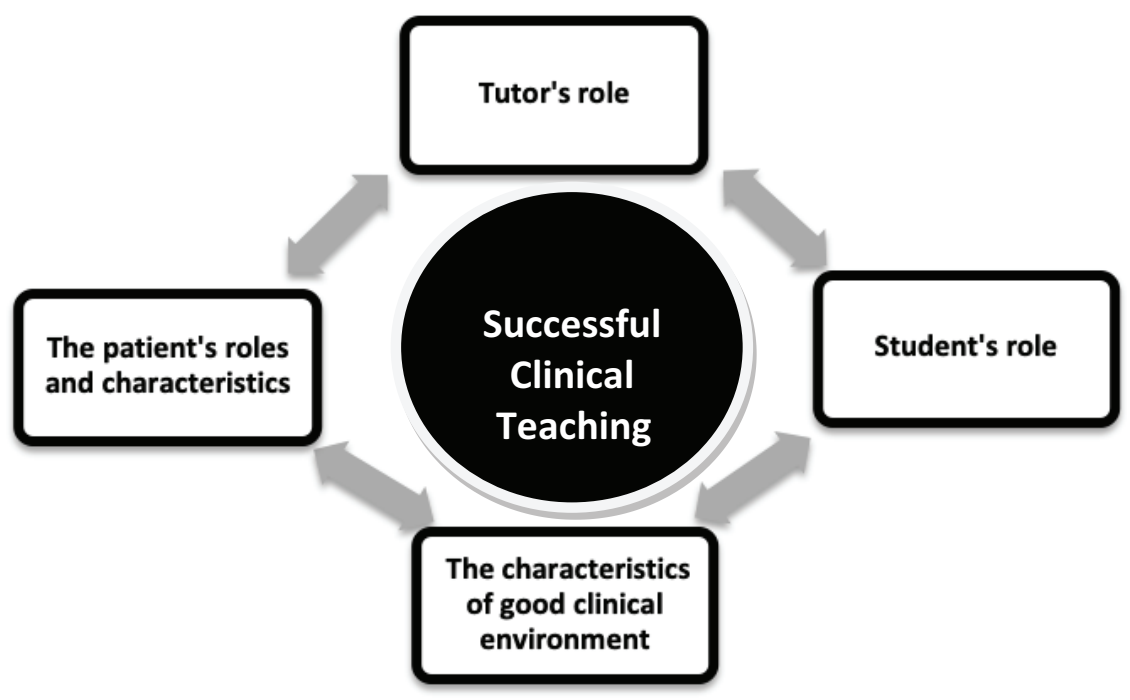

Figure 1: Clinical session preparation cycle.

\subsection{Tips related to the clinical tutor}

The clinical tutor should handle the session in a way that helps students gain the predetermined clinical competencies. Therefore, they should have the necessary skills, knowledge, and attitude [6, 7]. Frequently, tutors have other commitments like patients care, research, and administration that affect the planning and conduction of the session. It is therefore pertinent that the tutor plans the sessions in a way not to affect their duties but at the same time help students gain the required skills. The following are the perceived key tasks expected from the clinical tutor during and after the session, they are grouped under three headings: educational roles, organizational roles, and mentoring, as presented in Figure 2. 


\subsubsection{Educational roles}

1. Predetermine the time for teaching so that it does not overlap with other activities.

2. Leveling: Invest some time to know the students, their level and their previous clinical experiences.

3. Clearly define the training objectives of the clinical session and plan how to accomplish them.

4. Identify their educational strategies for each day.

5. Update their own skills before demonstration to students.

6. Demonstrate new clinical procedure that students have not seen before.

7. Provide students with hands-on opportunities under a direct supervision.

8. During the discussion, allow students to listen, observe, question, demonstrate, and participate.

9. Secure some time for students' reflection and feedback.

10. Demonstrate a professional attitude and approach toward both patients and students $[7,8]$.

11. At the end of the session, gather the students and summarize the session.

12. Reflect on the experience.

\subsubsection{Organizational role}

1. Communicate to students the required tasks to achieve their learning objectives.

2. Identify patients appropriate for the objectives of the session.

3. Seek consent from patients.

4. Secure a setting that is suitable for attaining the predetermined objectives.

5. Ensure that students have the required equipment.

6. Orient the students about wards, patients, and the available resources.

7. Brief the ward staff on what the students will do and provide the necessary support. 
8. Remind students to follow safety protocols (e.g., wash their hands carefully before and after examining patients.

9. Keep a record of the accomplished objectives.

10. Keep records of cases and skills gained by students.

11. Thank the hospital staff and patients for their cooperation.

12. Thank the students.

\subsubsection{Monitoring roles}

1. Be available and play an active role in facilitating students in learning to achieve the intended outcome.

2. During the students' experience, visit sites of training, observe them while carrying out the assigned tasks, record progress, provide feedback, and solve the arising problems.

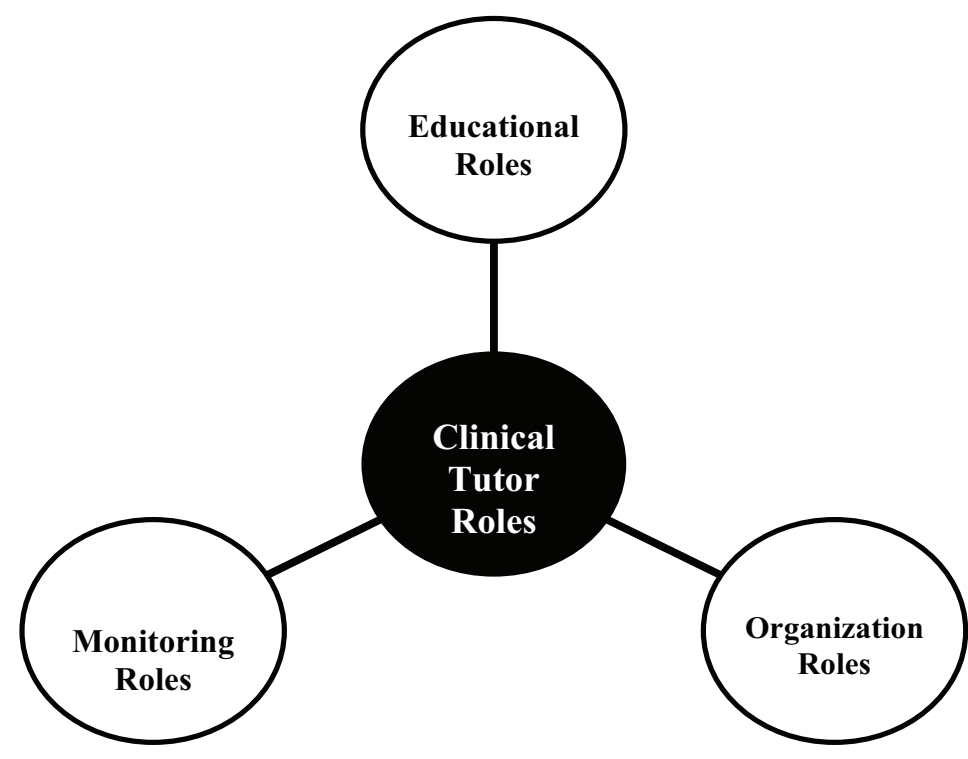

Figure 2: The triangular roles of the clinical tutor.

\subsection{Tips related to students}

Students have a major role in the success of the session. Good preparation will improve their learning and increase their engagement $[8,9]$. However, every too often, their 
preparation is suboptimal. Factors that negatively affect their preparation and engagement should be identified and resolved. The following are expected from students during their clinical rotation:

1. They must dress professionally and should wear their identification badges at all time.

2. Be punctual and on time.

3. Know the Code of Ethics and adhere to its principles.

4. Behave in a manner appropriate for medical students.

5. Ensure understanding the overall objectives of the clinical session and work toward achieving them.

6. Identify their specific learning objectives and work toward achieving them.

7. Ensure that patient consent is obtained.

8. Complete the clinical tasks assigned by their tutor.

9. Apply what they have previously learned in their clinical sessions

10. Maintain high standards of personal hygiene.

11. Maintain patients' confidentiality.

12. Actively participate in the discussion.

13. Communicate effectively with colleagues, patients, and tutors.

14. Keep up-to-date record of cases seen in their logbooks.

15. Give feedback to tutors after the session.

16. Thank the tutor, patient, and ward staff.

17. Reflect on the day's experience.

18. Develop their next clinical learning objectives.

\subsection{Tips related to clinical learning environment}

The CLE includes everything that surrounds students and affects their development in the clinical setting $[10,11]$. It is where the theoretical parts of the curriculum are integrated with the practical part [11, 12]. Adjusting the environment, therefore, is important to 
improve students' attainment of objectives and should not be left to chance $[12,13]$. Here are some of the characteristics of a good CLE:

1. A health facility which affiliates to a medical school or has a good collaboration and communication with it.

2. Has the resources and capacity to deliver safe and relevant learning.

3. Has a welcoming, supportive, and invitational staff who assist both students and tutors in achieving their goals.

4. Has a diverse patient population.

5. Has doctors with all levels of experiences (e.g., interns, residents, specialists, senior specialist, and consultant).

6. Is research-rich, wherein students can have the opportunity to be involved in research projects.

7. Is equipped to facilitate a hands-on experience under direct supervision.

8. Is technology-rich.

\subsection{Tips related to patients}

Patients are excellent teachers if used properly for the session, they are central to strengthening students' clinical skills. Most patients react positively to being part of student learning. They appreciate the opportunity to interact with the students [14]. Moreover, students are more motivated when meeting real patients. However, certain barriers might affect patient's participation in the session: (1) the nature and severity of the patient's disease, (2) previous negative experiences with students, (3) concern about confidentiality, (4) patient's education level, (5) lack of orientation, (6) the students' genders, and (7) students' attitudes [15-19]. These factors need consideration when planning the session. Furthermore, the patient-centered trend in clinical practice necessitates a different approach to involving patients in students training, precisely, more toward informed consent [20]. The following are to be considered when selecting patients for clinical session:

1. The patient should be clinically stable for history and examination

2. The patient's clinical problems should fit the learning objectives and the student's level. 
3. The patient should agree to take part in the session and be allowed to refuse or end participation.

4. Should be briefed about the session's objectives, number of students, and duration of the interview.

5. Patient's care should be assured throughout the interview time.

6. At the end of the session, students and tutors should give feedback to patients in a way that rewards them for their involvement [18].

7. If applicable, the patient should participate in students evaluation.

8. The patient should be empowered to provide feedback to students and tutors.

\section{Discussion}

Its argued that thorough descriptions of educational interventions are helpful for medical educators when translating good practices into their own practice [21]. The authors therefore developed a checklist for thorough description of roles of tutor, students, patients, and the learning environment in clinical teaching. Checklists are used frequently in our live, we prepare a shopping list and cross each item off when lifted. We list all important issues to be completed even before the day starts [22]. Therefore, Checklists are crucial to: (1) describe work routines and (2) guide decisions and tasks within such routines [23]. They are great in assuring that all important tasks are completed [22]. The field of medical education has benefited from using checklist, for example in OSCE. By doing SO, OSCE is considered to be one of the most robust methods used for clinical assessment across medical education as it reduces examiner bias due to the standardization of items and tasks for each candidate [24, 25, and 26, 27]. Not only in the field of medical education, but also in medical practice, checklists can significantly improve patient care and outcomes in term of reducing surgical site infections, postoperative complications and mortality [28, 29]. Conversely, in some situations checklists failed to provide some of the expected benefits. A study conducted by Heidi concluded that standardized patient OSCEs that are graded with a checklist probably do not effectively measure knowledge, clinical skill, or reasoning [30]. Hence, checklists should not be applied in all situations, particularly when unexpected events are frequent [23]. Four types of check lists were distinguished; the sequential, flowchart/diagnostic, criteria of merit list and the unstructured laundry list [31]. The developed checklist belongs to the structured laundry list as the purpose of this type of list is to serve as a memory aid 
to insure that required items (or steps to be performed) are present [31]. The next step should be to validate this checklist.

\section{Conclusion}

Clinical teaching is still the most attractive method of teaching clinical medicine to students. In this environment, students learn what it means to be a doctor [3]. Planning is a fundamental component of ward-based teaching. An attempt is made here to develop a checklist (tips) for thorough description of roles of tutor, students, patients, and the learning environment. If applied, it may contribute positively in the quality of the sessions; however, these tips should be designed by experts in the field.

\section{References}

[1] Irby, D. M. and Wilkerson, L. (2003). Educational innovations in academic medicine and environmental trends. Journal of General Internal Medicine, vol. 18, no. 5, p. 370.

[2] Šimunović, V. J., Hozo, I., Rakić, M., et al. (2010). New paradigm in training of undergraduate clinical skills (NEPTUNE-CS). Croatian Medical Journal, vol. 51, pp. 373-380.

[3] Ramani, S and Leinster, S. (2008). AMEE Guide no. 34: teaching in the clinical environment. Medical Teacher, vol. 30, pp. 347-364.

[4] General Medical Council. (2009). Tomorrow's Doctors: Outcomes and Standards For Undergraduate Medical Education. London: GMC. Available from: http://www.ub. edu/medicina_unitateducaciomedica/documentos/TomorrowsDoctors_2009.pdf

[5] Hales, B. M. and Pronovost, P. J. (2006).The checklist: a tool for error management and performance improvement. Journal of Critical Care, vol. 21, no. 3, pp. 231-235.

[6] Irby. D. M. (1994). What clinical teachers in medicine need to know? Academic Medicine, vol. 69, pp. 333-342.

[7] Ernstzen, D. V., Bitzer, E. M., and Grimmer-Somers, K. (2009). Physiotherapy students' and clinical teachers' perceptions of clinical learning opportunities: a case study. Medical Teacher, vol. 31, no. 3, pp. e102-e115.

[8] Valde, G. A. (1997). Promoting student participation and learning through the use of weekly writing assignments. Journal on Excellent College Teaching, vol. 8, no. 3, pp. 67-76. 
[9] Webb, N. M., Troper, J. D., and Fall, R. (1995). Constructive activity and learning in collaborative small groups. Journal of Educational Psychology, vol. 87, no. 3, pp. 406-423.

[10] Papastavrour, E., Dimitriadou, M., Tsangari, H., et al. (2016). Nursing students' satisfaction of the clinical learning environment: a research study. BMC Nursing, vol. 15, p. 44. DOI: 10.1186/s12912-016-0164-4.

[11] Steven, A., Magnusson, C., and Smith, P. (2014). Patient safety in nursing education: contexts, tensions and feeling safe to learn. Nurse Education Today, vol. 34, pp. 277-284.

[12] Aalbers, M. W., Hommes, J., Rethans, J., et al. (2013). Why should I prepare? A mixed method study exploring the motives of medical undergraduate students to prepare for clinical skills training sessions. BMC Medical Education, vol. 13, no. 1, pp. 1-9.

[13] McLeod, P. J. and Harden, R. M. (1985). Clinical teaching strategies for physicians. Medical Teacher, vol. 7, pp. 173-189.

[14] Carman, D. and Britten, N. (1995). Confidentiality of medical records: the patient's perspective. British Journal of General Practice, vol. 45, pp. 485-488.

[15] Shah-Khan, M., Chowdhry, S., Brand, M. I., et al. (2007). Patient attitudes toward medical students in an outpatient colorectal surgery clinic. Diseases of the Colon \& Rectum, vol. 50, pp. 1255-1258.

[16] Abdulghani, H. M., Al-Rukban, M. O., and Ahmad, S. S. (2008). Patient attitudes towards medical students in Riyadh, Saudi Arabia. Education for Health, vol. 21, p. 69.

[17] Howe, A. and Anderson, J. (2003). Involving patients in medical education. BMJ, vol. 327, pp. 326-328. DOI: 10.1136/bmj.327.7410.326.

[18] Al Ghobain, A., Alghamdi, A., Arab, A., et al. (2016). Patients' perceptions towards the participation of medical students in their care. Sultan Qaboos University Medical Journal, vol. 16, no. 2, pp. e224-e229.

[19] Wright, H. J. (1974). Patients' attitudes to medical students in general practice. BMJ, vol. I, pp. 372-376.

[20] Gierk, B. and Harendza, S. (2012). Patient selection for bedside teaching: inclusion and exclusion criteria used by teachers. Medical Education, vol. 46, no. 2, pp. 228 233. DOI: 10.1111/j.1365-2923.2011.04054.

[21] Meinema JG, Buwalda N, van Etten-Jamaludin FS, Visser MRM, van Dijk N. (2019). Intervention Descriptions in Medical Education: What Can Be Improved? A Systematic Review and Checklist. Acad Med, 94(2):281-290. 
[22] Explorer Surgical. (October 17, 2018). Why Medical Checklists Are Important. Available from: https://explorersurgical.com/blog/medical-checklists-are-important/

[23] Reijers, H., Leopold, H., and Recker, J. (2017). Towards a science of checklists. Proceedings of the 50th Hawaii International Conference on System Sciences. Available from: https://core.ac.uk/download/pdf/301371513.pdf

[24] Chong L, Taylor S, Haywood M, Adelstein BA, Shulruf B. (2017). The sights and insights of examiners in objective structured clinical examinations. J Educ Eval Health Prof. 2017 Dec 27;14:34. doi: 10.3352/jeehp.14.34. PMID: 29278906; PMCID: PMC5801428.

[25] Sakurai H, Kanada Y, Sugiura Y, Motoya I, Wada Y, Yamada M, Tomita M, Tanabe S, Teranishi T, Tsujimura T, Sawa S, Okanishi T. (2014). OSCE based clinical skill education for physical and occupational therapists. J Phys Ther Sci.;26:1387-1397.

[26] Brennan PA, Croke DT, Reed M, Smith L, Munro E, Foulkes J, Arnett R. (2016. Does changing examiner stations during UK postgraduate surgery objective structured clinical examinations influence examination reliability and candidates' scores? J Surg Educ.;3:616 623.

[27] Hofer RE, Nikolaus OB, Pawlina W. (2011). Using checklists in a gross anatomy laboratory improves learning outcomes and dissection quality. Anat Sci Educ 4, 249-255.

[28] Pronovost, P., Needham, D., Berenholtz, S., et al. (2006). An intervention to decrease catheter-related bloodstream infections in the ICU. New England Journal of Medicine, vol. 355, pp. 2725-2732.

[29] Haynes, A. B., Weiser, T. G., Berry, W. R., et al. (2009). A surgical safety checklist to reduce morbidity and mortality in a global population. New England Journal of Medicine, vol. 360, pp. 491-499

[30] Chumley, Heidi. (2008). What does an OSCE checklist measure? Family medicine. 40. 589-91.

[31] Kramer Heidi S. and Drews Frank A. (2016). Checking the lists: A systematic review of electronic checklist use in health care. Journal of Biomedical Informatics. 10.1016/jjbL.09.006 